\title{
Influence of Stress and Temperature on Adhesively Bonded Joints in and After Heat-curing Processes
}

\author{
D. Teutenberg ${ }^{1 *}$, G. Meschut ${ }^{1}$, O. Hahn ${ }^{1}$, M. Schlimmer ${ }^{2}$ \\ P. Kuehlmeyer ${ }^{3}$ and A. Matzenmiller ${ }^{3}$
}

Key words : curing process, toughened adhesive, temperature change, residual stresses

\section{Introduction}

Structural adhesives are used to improve the mechanical properties of cars in automotive production. Therefore, the car body is heated in order to cure its adhesive joints. In light weight design, various materials with different thermal expansions are joined to a car body leading to stresses within the adhesive, which may cause damage in the bond. During the cooling process of the car body, relative displacements occur between the joint partners resulting joint failure. Thereafter, the components of the car body are repeatedly loaded by thermal and mechanical stresses due to subsequent operation loads. Then, the accumulation of resultant inelastic deformations can cause adhesive failure, too. In a recently completed research project, the necessary experimental and numerical investigations are performed to identify the stresses in adhesive joints caused by thermal expansion of adherends during and after curing and subsequent operating loads.

\section{Experimental set up}

Thick Adherend Shear Specimens (TASS), butt joint and bimetallic specimens are tested. The latter consists of an aluminium and a steel sheet metal strip with different thermal expansion coefficients. Both strips are joined with an uncured and a cured adhesive layer at the right hand side whereas they are clamped at the

1 LWF, University of Paderborn, Pohlweg 47-49, 33098 Paderborn, Germany,

E-mail: dominik.teutenberg@1wf.upb.de, Tel: +495251 605282

2 WWV Consulting Forschung Klebtechnik GmbH, Wilhelmshoeher Str. 67, 34225 Baunatal, Germany

3 IfM, University of Kassel, Moenchebergstr. 7, 34125 Kassel, Germany

(Received : December 18, 2014) left hand side as shown in Fig. 1. When heat is applied, the different thermal expansions of the adherends lead to shear deformations in the adhesive. So, the bimetal specimen is tested to evaluate the mechanical properties of the adhesive during cure and for the cured joint under arbitrary thermal conditions. Finally, the test data of the bimetal specimen with the cured adhesive are used for the validation of a constitutive model for the adhesive joint ${ }^{1)}$.

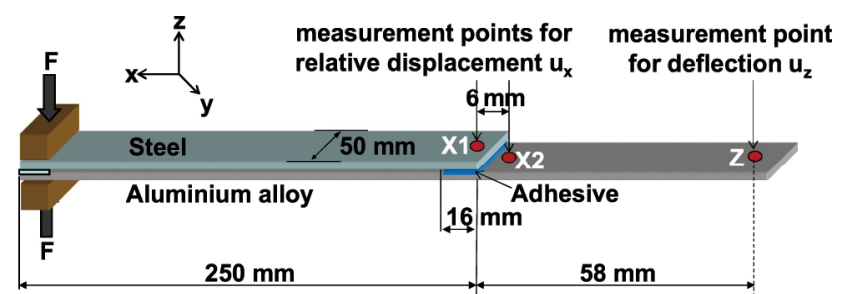

Fig. 1 Bimetal specimen ${ }^{1)}$

\section{Results and Discussion}

Cured and uncured adhesives are tested under arbitrary displacement-time and temperature-time profiles. In Fig. 2 (a), the influence of a cured adhesive on the stress-strain relationship is evaluated for different constant temperature states under a quasi-static linear displacement-time curve. The yield threshold and the shear strength steadily decrease with increasing temperature, whereas the critical strain, being at the shear strength, increases. Furthermore, the slope of the plastic hardening is nearly constant in temperature. However, the data for the temperatures of $100^{\circ} \mathrm{C}$ and $110^{\circ} \mathrm{C}$ are different from that for lower temperatures. Instead, their stress-strain courses are approximately linear until the maximum stress is reached. This is due to the temperature conditions of the tests, being in the range of the glass transition point of the adhesive. 


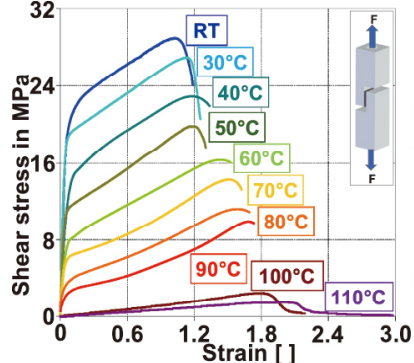

(a)

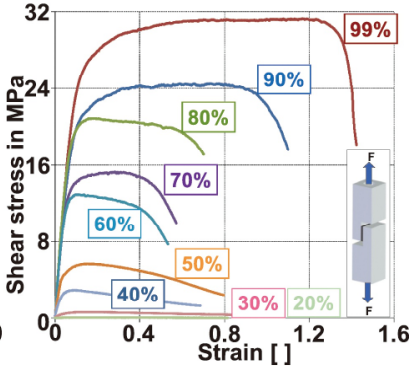

(b)
Fig. 2 Stress-strain curves for different temperature (a) and cure (b) ${ }^{1)}$

The influence of the degree of cure on the stressstrain relationship is shown with the test data of the TASS. At first, the exothermic reaction of the adhesive is examined by using the Differential Scanning Calorimetry (DSC $)^{1)}$ to determine the degree of cure as a function of temperature and time. Then, the adhesive of the TASS is cross-linked under defined timetemperature curves from $20 \%$ to $99 \%$. As shown in Fig. 2 (b), the mechanical properties of the adhesive joint heavily depend on the degree of cure. Especially, the yield threshold, the shear strength, the fracture strain, and the plastic hardening course of the adhesive are influenced. For an indirect evaluation of the stress in the cured adhesive of the bimetal specimen, the deflection at the tip $u_{z}$ is measured under a typical time-temperature loading, described by a linear heating process up to $80^{\circ} \mathrm{C}$ in $6 \mathrm{~min}$, followed by a hold time at $80^{\circ} \mathrm{C}$ for $125 \mathrm{~min}$, and an uncontrolled cooling process up to room temperature. Fig. 3 shows the data of the deflection $u_{z}$ of four tests, being in the range from $8 \mathrm{~mm}$ to $10 \mathrm{~mm}$ at the end of the heating process. For the constant temperature state, they decrease to approximately constant values between $6 \mathrm{~mm}$ and 8 $\mathrm{mm}$, caused by stress relaxation against the equilibrium stress in the adhesive. Furthermore, $u_{z}$ drops below its initial value after cooling down to room temperature, caused on residual inelastic strains. Besides, the butt joint specimen is tensile-tested for different constant temperatures and degrees of cure.

The bimetal specimen with the cured adhesive is simulated using the FE-program LS-DYNA ${ }^{3)}$. Both sheets are spatially discretised by enhanced solid elements with elastic material properties, while a user defined thermoviscoelastic-plastic model is implemented for the interface element in ${ }^{3)}$ to model the thin bonding layer. The model approach consists of a generalised MAXWELL solid in series with a thermal strain element and a ST.-VENANT body with temperature dependent nonlinear isotropic hardening, based on the TAPO-model in ${ }^{2)}$ and also MAT_252 in ${ }^{3)}$. The tempera-

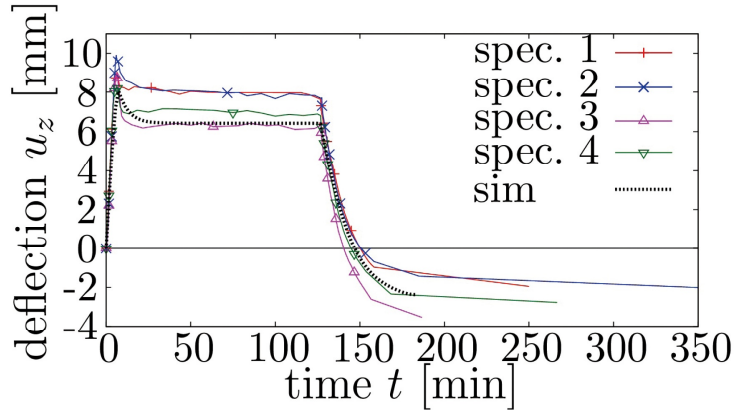

Fig. 3 Measured and simulated deflection at tip of bimetal specimen

ture dependent viscosity rests upon thermorheologically simple material behaviour. The structural adhesive is discretised with interface elements, defined between the solid elements of the sheets using a node to node connection ${ }^{1)}$. Furthermore, the experimental temperature-time course is prescribed for all nodes of the FE-model. The simulation provides the deflection $u_{z}$ in comparison to the measurements of the tests-see Fig. 3 . As a result, the FE simulation is in good agreement with the measured test data.

\section{Conclusions}

Tests with the TASS, the butt joint and the bimetal specimen evaluate the stresses in the adhesively bonded joint due to relative displacements during and after cure. As a result, the mechanical properties of the joint depend on cure and temperature heavily. With the bimetallic specimen, the stress relaxation is indirectly evaluated through the deflection $u_{z}$ with respect to temperature, deformation, and time. Finally, the test data of the bimetal specimen validate the interfacial constitutive model successfully.

\section{Acknowledgements}

We acknowledge the financial support of the Federal Ministry for Economic Affairs and Energy through the $\mathrm{AiF}^{\dagger}$ by grant $\mathrm{P} 878 / 369 \mathrm{ZN}$ of the $\mathrm{FOSTA}^{\dagger \dagger}$.

\section{References}

1) A. Lion, A. Matzenmiller, G. Meschut: FOSTA-Report P 878, (2014), in press ${ }^{\mathrm{t+}}$

2) M. Brede, P. Gumbsch, A. Matzenmiller, R. Mahnken, K. Thoma: FOSTA-Report P828, (2014), in press ${ }^{\text {ttt }}$

3) LS-DYNA: Keyword user's manual, LSTC, May 26, 2014

$\dagger$ Arbeitsgemeinschaft industrieller Forschungsvereinigungen "Otto von Guericke" e.V.

$\dagger^{\dagger}$ Forschungsvereinigung Stahlanwendung e. V., Sohnstr. 65, 40237 Duesseldorf, Germany

$\dagger^{\dagger} \dagger$ Download author created reports of IfM, University of Kassel at: www.uni-kassel.de/maschinenbau/institute/ mechanik/fachgebiete/numerische-mechanik/ publikationen.html 